\title{
PERFIS TEMPORAIS NDVI MODIS, NA CANA-SOCA, DE MATURAÇÃO TARDIA
}

\section{FERNANDO L. P. RAMME ${ }^{1}$, RUBENS A. C. LAMPARELLI ${ }^{2}$, JANSLE V. ROCHA ${ }^{1}$}

RESUMO: Este artigo descreve o desenvolvimento de um banco de dados relacional e de uma ferramenta para a visualização de perfis temporais do NDVI MODIS, a partir dos dados do produto MOD09Q1, referente ao fator de refletância bidirecional de superfície relativa ao comprimento de onda do vermelho e do infravermelho-próximo, composição temporal em mosaicos de 8 dias, e a banda de controle de qualidade, dos talhões de cana-de-açúcar no Estado de São Paulo, para analisar a maturação da cana-soca Tardia. Das fazendas de cana-de-açúcar são obtidos os dados de históricos sobre produtividade, solo, variedade, localização de cada pixel para cada microrregião monitorada. Todos os dados são integrados em um banco de dados desenvolvido em PostgreSQL. O aplicativo foi implementado usando a linguagem Java e permitiu uma forma rápida e automática para analisar padrões fenológicos na cana-de-açúcar. Concluiu-se que o perfil temporal do NDVI MODIS obtido a partir do produto MOD09Q1 é capaz de subsidiar o monitoramento das mudanças fenológicas na cultura da cana-de-açúcar.

PALAVRAS-CHAVE: MODIS, curvas espectrais, índice de vegetação, cana-de-açúcar.

\section{NDVI MODIS TEMPORAL PROFILES, IN SUGARCANE, LATE MATURATION}

\begin{abstract}
This paper describes the development of a relational database and a tool for viewing MODIS NDVI temporal profile, using data from MOD09Q1 product, specifically the surface bidirectional reflectance factor relative to the RED and NIR wavelength, mosaic of 8-day temporal composition, and the quality band, in sugarcane fields in the state of São Paulo, for analysis of the late stubble-cane maturation. From sugarcane farms were obtained the historical data about yield, soil, variety, location of the each pixel for each subregion monitored. All data were integrated in a database developed in PostgreSQL. The tool was implemented using Java language and allowed a fast and automatic way of analyzing sugarcane phenological patterns. It concluded that the MODIS NDVI temporal profile using data from MOD09Q1 product is able to subsidize the monitoring of phenological changes in the sugarcane.
\end{abstract}

KEYWORDS: MODIS, spectral curves, vegetation index, sugarcane.

\section{INTRODUÇÃO}

Índices de vegetação podem ser definidos como a combinação de dados de bandas espectrais, selecionadas com o objetivo de realçar a relação desses dados com os parâmetros da vegetação. Para minimizar a variabilidade causada por fatores externos, a reflectância espectral tem sido combinada em vários índices de vegetação (PONZONI, 2001). Na prática, a importância do índice de vegetação NDVI está em sua existência de relação com vários parâmetros biofísicos da vegetação, ou seja, na possibilidade de se estimarem parâmetros como o índice de área foliar (IAF) (PELLEGRINO et al., 2007; SIMÕES et al., 2005; BENVENUTI, 2005), a biomassa vegetal (TUCKER, 1979) e a produtividade (SIMÕES et al., 2009; PELLEGRINO et al., 2007; SIMÕES et al., 2005; BENVENUTI, 2005; RUDORFF \& BATISTA, 1990). Pode-se acrescentar, ainda, a correlação dos índices de vegetação com outros parâmetros, como a radiação fotossinteticamente ativa absorvida (PAR) ou a fração da rdffdadiação fotossinteticamente ativa absorvida pelo dossel ( $f$ APAR) (EPIPHANIO \& HUETE, 1994), e a porcentagem de cobertura verde (COV) (ELVIDGE

\footnotetext{
${ }^{1}$ Faculdade de Engenharia Agrícola, FEAGRI/UNICAMP, Campinas - SP, framme@ hotmail.com, jansle.rocha@ feagri.unicamp.br.

${ }^{2}$ Centro de Pesquisas Meteorológicas e Climáticas Aplicadas à Agricultura, CEPAGRI/UNICAMP, Campinas - SP, rubens@cpa.unicamp.br. 
\& CHEN, 1995). A biomassa verde de uma comunidade de plantas pode ser diretamente relacionada ao índice de área foliar (TURNER et al., 1999) que, por sua vez, é positivamente correlacionado com a quantidade de clorofila por unidade de área (CASAGRANDE, 1991; DILLEWIJN, 1952) e, também, com o grau de recobrimento do solo (BENVENUTI, 2005).

A normalização proposta por ROUSE et al. (1973) visou a eliminar diferenças sazonais do ângulo do Sol e minimizar os efeitos da atenuação atmosférica e o problema das interferências do solo na resposta da vegetação, observados para dados multitemporais. Com esta normalização, a partir dos valores entre 0 e 1 do fator de refletância bidirecional de superfície relativa ao comprimento de onda do vermelho (RED) e do infravermelho-próximo (NIR), obtém-se o índice NDVI que está contido em uma escala de valores entre -1 e 1. HUETE et al. (1999) citam que o NDVI é um índice que é dependente do conteúdo de aerossol (fumaça, poeira e poluição) na atmosfera. Para esse índice, adota-se a seguinte expressão:

$$
\mathrm{NDVI}=(\mathrm{NIR}-\mathrm{RED}) /(\mathrm{NIR}+\mathrm{RED})
$$

Este artigo teve o objetivo de desenvolver um banco de dados relacional e de uma ferramenta computacional para que proporcionasse a visualização do perfil temporal do NDVI, a fim de analisar a existência de padrões durante o desenvolvimento fenológico da cultura, especificamente na cana-soca de maturação tardia.

\section{MATERIAL E MÉTODOS}

A região monitorada no trabalho compreende algumas fazendas localizadas em torno dos municípios de Irapuã e Borborema, no Estado de São Paulo. A área de estudo ilustrada na Figura 1 possui coordenadas geográficas dos cantos: inferior direito LAT/LONG $\left(-23,22^{\circ} ;-46,86^{\circ}\right)$ e superior esquerdo LAT/LONG $\left(-20,69^{\circ} ;-49,62^{\circ}\right)$, na projeção Geográfica, datum WGS-84. A cana-de-açúcar (DILLEWIJN, 1952) é a cultura utilizada no trabalho.

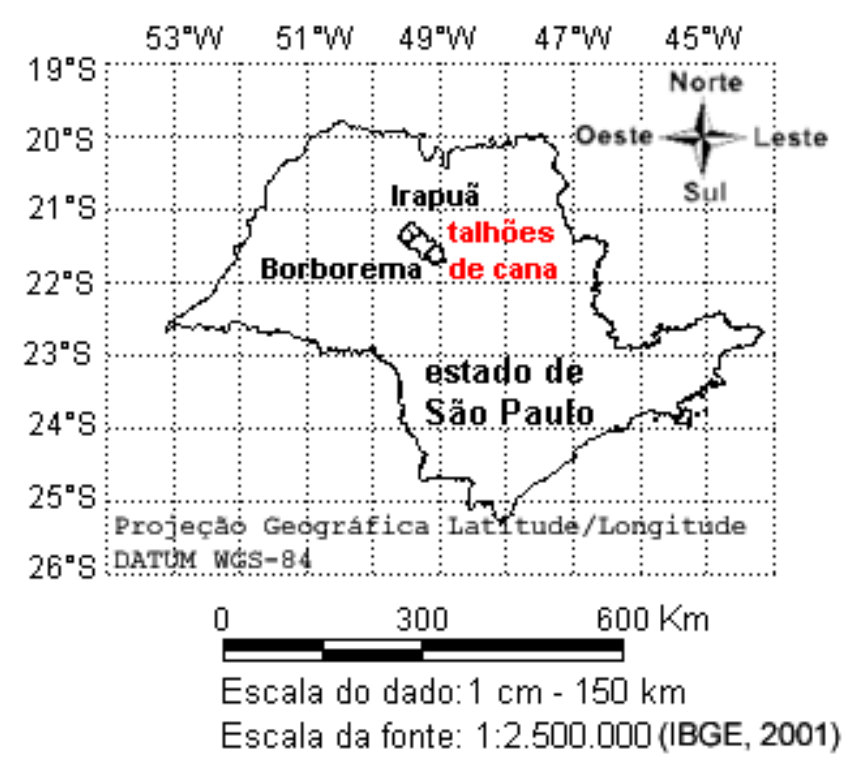

FIGURA 1. Localização da área de estudo do trabalho. Study area location.

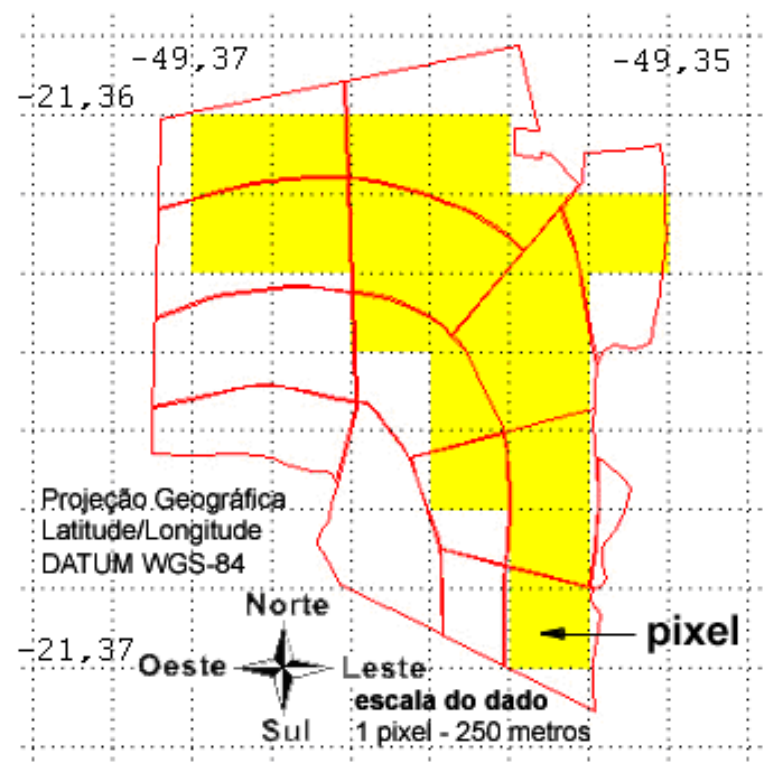

FIGURA 2. Seleção dos pixels em uma microrregião. Pixel selection within a microregion.

A variedade escolhida foi a RB 72-454, uma das mais representativas na área de estudos com as características descritas na Tabela 1. 
TABELA 1. Características da variedade RB 72-454. Characteristics of RB 72-454 variety.

\begin{tabular}{cccccccc}
\hline Variedade & Porte & $\begin{array}{c}\text { Hábito de } \\
\text { Crescimento }\end{array}$ & $\begin{array}{c}\text { Fechamento } \\
\text { Entre Linhas }\end{array}$ & Tombamento & $\begin{array}{c}\text { Produção } \\
\text { Agrícola }\end{array}$ & Maturação & $\begin{array}{c}\text { Época de } \\
\text { Corte }\end{array}$ \\
\hline RB72-454 & médio & ereto & bom & raro & alta & tardia & $\begin{array}{c}\text { setembro a } \\
\text { novembro }\end{array}$ \\
\hline
\end{tabular}

As microrregiões avaliadas no trabalho são identificadas com os códigos M3, M4, M5, M6 e M9, conforme apresentado na Figura 3.

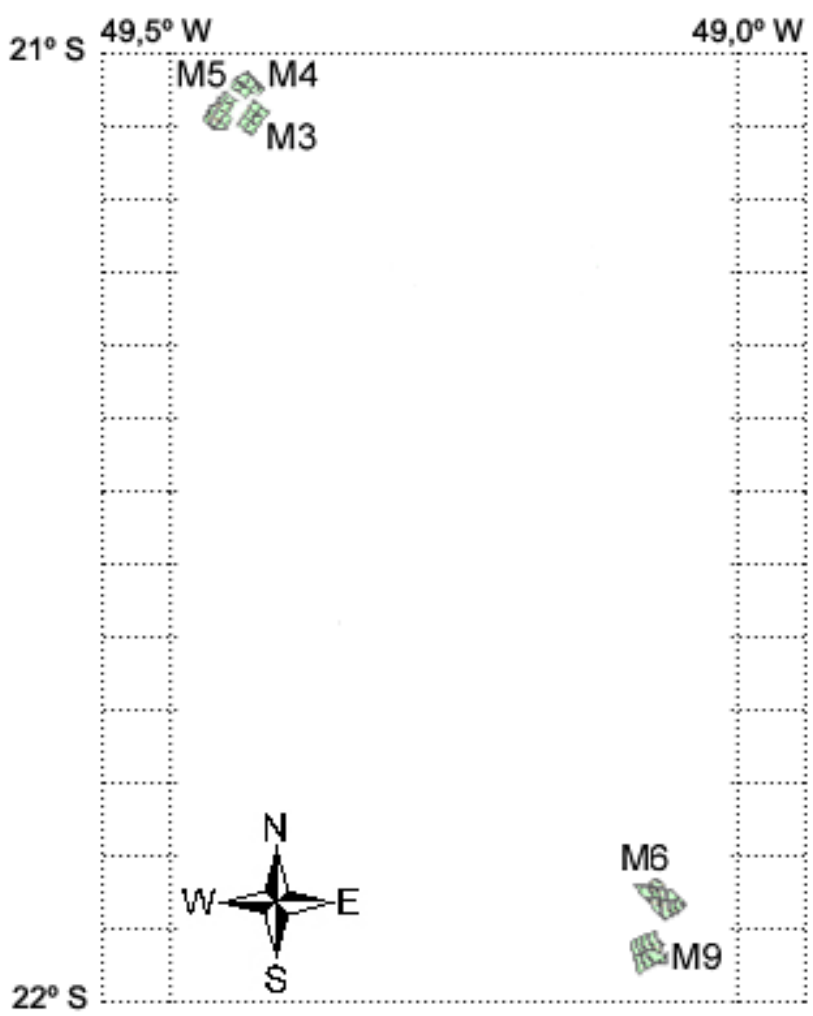

FIGURA 3. Visão espacial das microrregiões avaliadas no trabalho. Spatial visualization of microregions evaluated in this study.

Nas regiões monitoradas, os dados das safras de cana-soca em 2004/2005 e 2005/2006 foram obtidos da usina de cana-de-açúcar para cada talhão: identificação do talhão, variedade, solo, fazenda, data de plantio, data de corte, produtividade e estágio da cana. Os dados adquiridos são validados e armazenados no banco de dados estruturado para este trabalho no esquema schUsina. A consistência dos dados é requerida porque os dados foram adquiridos no formato tabular, um único arquivo contendo os atributos para cada safra em formato $D B A S E$, e vetorial referente aos talhões de cana-de-açúcar, arquivo em formato Shapefile.

A microrregião 3 possui a variedade RB 72-454, solo do tipo LVA-7 - Latossolo VermelhoAmarelo, eutrófico típico, textura média, A moderado, relevo suave ondulado a plano, safra 2005/2006 de terceiro corte, em 11 de novembro de 2006, com 60,3 $\mathrm{t} \mathrm{ha}^{-1}$.

A microrregião 5 possui a variedade RB 72-454, caracterizada pelo crescimento ereto, solo do tipo LVA-8 - Latossolo Vermelho-Amarelo, distrófico típico, textura média, A moderado, relevo suave ondulado a plano. A safra de 2004/2005 é de segundo corte, em 28 de novembro de 2005, e a produtividade obtidade foi de $88,2 \mathrm{t} \mathrm{ha}^{-1}$. A safra de 2005/2006 é de terceiro corte, em 11 de novembro de 2006, e a produtividade obtida foi de $62,0 \mathrm{t} \mathrm{ha}^{-1}$.

O solo da microrregião 4 é classificado como PVA-13 - Argissolo Vermelho-Amarelo, eutrófico típico, textura média, A moderado, relevo ondulado a suave ondulado. A variedade é a RB 72-454. A safra de 2004/2005 é de segundo corte, em 25 de novembro de 2005, e a produtividade 
obtida foi de 84,0 $\mathrm{t} \mathrm{ha}^{-1}$. A safra de 2005/2006 é de terceiro corte, em 11 de novembro de 2006, e a produtividade obtida foi de $67,0 \mathrm{t} \mathrm{ha}^{-1}$.

A microrregião 6 possui a variedade SP 83-2847, solo LVA-9 - Latossolo VermelhoAmarelo, distrófico típico, textura média, álico, A moderado, relevo suave ondulado a plano. A safra 2005/2006 é de segundo corte, em 21 de agosto de 2006, e a produtividade obtida foi de $90,0 \mathrm{t} \mathrm{ha}^{-1}$.

A microrregião 9 possui a variedade RB 72-454, solo LVA-8 - Latossolo Vermelho-Amarelo, distrófico típico, textura média, A moderado, relevo suave ondulado a plano. A safra 2005/2006 é de segundo corte, em 5 de agosto de 2006, e a produtividade obtida foi de 81,0 t ha ${ }^{-1}$.

Problemas comumente encontrados em dados no formato tabular são: a presença de dados incompletos, dados redundantes, dados inconsistentes como a presença de zero em campos em que de fato ainda não ocorreu a atribuição de valores e/ou valores fora do domínio aceitável, conforme as regras de negócio do sistema e ausência de restrições de integridade de entidade, referencial e de domínio. As restrições de integridade são regras que definem a validade dos dados. Uma base de dados está num estado de integridade quando contém apenas dados válidos, e os dados armazenados estão de acordo com a realidade.

A consistência dos dados foi realizada de forma manual. O conceito de temporalidade sobre os dados importados, a partir de cada arquivo tabular em formato DBASE, é incorporado durante a importação dos dados para o sistema gerenciador de banco de dados (SGBD) relacional PostgreSQL, utilizado no trabalho, através do preenchimento de tabelas auxiliares que armazenam a identificação do histórico das datas de corte da cana-de-açúcar em cada safra e para cada talhão. A adotação de um SGBD permitiu o armazenamento persistente e temporal dos dados, e maior flexibilidade em utilizar softwares diversos quanto ao acesso através de uma linguagem de consulta padronizada $S Q L-92$, manipulação, inspeção e geração de relatórios a partir dos dados contidos no banco de dados.

O tile H13V11, do produto Refletância de Superfície MOD09 (MODIS/TERRA), cobre a região de interesse para a cultura da cana-de-açúcar, durante as safras de 2004/2005 e 2005/2006. As imagens das bandas do vermelho, infravermelho-próximo e controle de qualidade, versão 4, resolução temporal com composição de oito dias, foram adquiridas em USGS/LPDAAC (2007), nos anos de 2004, 2005 e 2006.

Para o processamento, análise dos dados e das imagens MODIS/TERRA, foram utilizados os programas: 1) Modis Reprojection Tool, para a extração das bandas de interesse, recorte das imagens e reprojeção dos dados para a projeção geográfica LAT/LONG e datum WGS-1984, graus decimais; 2) ENVI, para a seleção dos pixels desejados na região em estudo, conforme ilustrado na Figura 2; e 3) PostgreSQL, como o sistema gerenciador de banco de dados (SGBD).

Através de um programa (script) desenvolvido neste trabalho, executado sobre o software MODIS Reprojection Tool, realiza-se o recorte da região de estudo sobre toda a série temporal de imagens MODIS. Após a finalização desta etapa, a extração dos valores dos pixels das bandas do vermelho, do infravermelho-próximo e de controle de qualidade do produto MOD09Q1, nas regiões monitoradas, é realizada de forma automática, via programa desenvolvido para este trabalho, para toda a série temporal de dados. Para cada valor de pixel extraído de uma banda de imagem, é armazenado, conforme ilustrado na Figura 4, juntamente: a identificação da microrregião, o código do produto MODIS, o identificador de posição do pixel e a data da imagem. A extração dos bits da banda de controle de qualidade (QC) ocorre posteriormente aos valores dos pixels estarem armazenados no banco de dados, através de programa desenvolvido para este trabalho.

A fim de armazenar os dados de localização cartesiana, expressa em X e Y, dos pixels selecionados para o monitoramento temporal, o primeiro esquema do banco de dados implementado foi nomeado de schRegião. De posse dos vetores, em formato de arquivo Shapefile, representativos dos talhões, adquirido da usina de cana-de-açúcar, com o aplicativo de processamento de imagens 
ENVI, analisam-se as microrregiões candidatas, conforme Figura 2, e a localização dos pixels "puros", área do pixel ocupada inteiramente por cana e compreendido em sua totalidade dentro dos talhões agrupados em uma microrregião com características comuns, desejados para o monitoramento em cada microrregião, que, posteriormente, são armazenados no esquema schRegião do banco de dados.

Uma microrregião, neste trabalho, corresponde a um conjunto de talhões com características comuns segundo determinados critérios. Os critérios adotados para a formação de uma microrregião neste trabalho são: 1) talhões contíguos sob o mesmo ambiente (solo e variedade); 2) talhões contíguos sob a presença da cultura da cana-de-açúcar; e 3) período de corte entre os talhões não superior a oito dias. O critério conservador, a fim de evitar influências na interpretação do comportamento do alvo em estudo, adotado para a seleção dos pixels, na resolução espacial de $250 \times 250 \mathrm{~m}$, consiste em selecionar apenas o pixel que possua cobertura da área superior a $75 \%$ do alvo desejado internamente ao vetor dos talhões.

O banco de dados do trabalho é constituído de três esquemas: 1) schUsina; 2) schRegião; e 3) schPixel. No esquema schUsina, os dados das safras de 2004/2005 e 2005/2006 foram obtidos da usina Santa Elisa para cada talhão: identificação do talhão, variedade, solo, fazenda, data de plantio, data de corte, produtividade e estágio da cana. Uma usina de cana-de-açúcar pode possuir várias fazendas sob monitoramento e cada uma dessas fazendas está relacionada a um conjunto de talhões. Em cada agrupamento de talhões (talhões contíguos), tem-se uma microrregião de estudo. $\mathrm{O}$ conjunto de microrregiões é armazenado no esquema schRegião. No esquema schRegião, os dados de localização escalar, expressa em X e Y, dos pixels selecionados para o monitoramento temporal estão armazenados. No esquema schPixel, a evolução temporal dos dados das bandas de refletância de superfície do vermelho, de refletância de superfície do infravermelho-próximo e de controle de qualidade estão disponíveis para que o aplicativo cliente desenvolvido neste trabalho realize consultas via linguagem Structured Query Language (SQL-92) ao servidor onde se encontra o SGBD PostgreSQL.

O esquema schPixel é constituído pelas tabelas: imagem e imagem_qc. A tabela denominada imagem, ilustrada na Figura 4, é responsável por armazenar o valor de cada pixel para as bandas RED, NIR e QC da imagem MODIS do produto MOD09Q1 versão 4, e relacioná-lo: ao identificador único da microrregião, ao código do produto-imagem, a um identificador incremental de sequência do pixel na microrregião e à data da imagem MODIS. A extração dos dados de nível de cinza (NC) de cada pixel das bandas RED, NIR e QC, temporalmente, é realizada de forma automática através de software desenvolvido neste trabalho. A tabela denominada imagem_qc é responsável por armazenar os valores de controle de qualidade avaliados posteriormente de cada pixel da banda QC das imagens MODIS. As seguintes características de qualidade do pixel são armazenadas na tabela imagem_qc para posterior utilização em filtragem dos ruídos: avaliação da qualidade de imageamento do pixel da superfície da terra, qualidade referente à presença de nuvens, qualidade de imageamento do pixel na banda vermelho, qualidade de imageamento do pixel na banda infravermelho-próximo, qualidade da correção atmosférica e a qualidade da correção dos efeitos provocados pelos pixels da adjacência.

O banco de dados implementado no trabalho possibilita extrair perfis temporais do NDVI na cultura da cana-de-açúcar. A modelagem concebida para o banco de dados é de fácil entendimento para o usuário, propicia integridade aos dados, possibilita obter alto desempenho para as consultas aos dados, atende aos requisitos do estudo de caso deste trabalho e é acessível por qualquer software, incluindo os SIGs, através da linguagem de consulta padronizada SQL-92. 


\begin{tabular}{|l|l|l|l|l|}
\hline $\begin{array}{l}\text { oid_microregiao } \\
\text { smallint }\end{array}$ & $\begin{array}{l}\text { cod_produtosig } \\
\text { character varying(30) }\end{array}$ & $\begin{array}{l}\text { oid_pixelpos } \\
\text { smallint }\end{array}$ & $\begin{array}{l}\text { dataimg } \\
\text { date }\end{array}$ & $\begin{array}{l}\text { pixel_valor } \\
\text { integer }\end{array}$ \\
\hline 1 & MOD09Q1.004.0250m.NIR & 1 & $2004-01-01$ & 4789 \\
\hline 1 & MOD09Q1.004.0250m.QC & 1 & $2004-01-01$ & 4100 \\
\hline 1 & MOD09Q1.004.0250m.RED & 1 & $2004-01-01$ & 1832 \\
\hline 1 & MOD09Q1.004.0250m.NIR & 2 & $2004-01-01$ & 4789 \\
\hline 1 & MOD09Q1.004.0250m.QC & 2 & $2004-01-01$ & 4100 \\
\hline 1 & MOD09Q1.004.0250m.RED & 2 & $2004-01-01$ & 1832 \\
\hline 1 & MOD09Q1.004.0250m.NIR & 3 & $2004-01-01$ & 4841 \\
\hline 1 & MOD09Q1.004.0250m.QC & 3 & $2004-01-01$ & 4100 \\
\hline
\end{tabular}

FIGURA 4. Exemplo de dados armazenados na tabela imagem. Example of data storage in imagem table.

\section{Filtragem de ruídos no perfil temporal do NDVI MODIS}

Durante a consulta aos dados do perfil temporal do NDVI contidos no banco de dados, esquema schPixel, é requerido realizar uma filtragem dos dados e posterior suavização devido aos ruídos ainda presentes na série temporal. A filtragem dos dados consiste em remover ruídos, pixels com valores de NDVI espúrios, de forma a promover uma evolução suave do perfil temporal do NDVI MODIS. Neste trabalho, são considerados ruídos os distúrbios ou deformações bruscas e isoladas temporalmente no comportamento do alvo em estudo (cana-de-açúcar), ao longo do ciclo da cultura no perfil NDVI analisado. Esses ruídos podem ocorrer na evolução do perfil NDVI devido a diversos fatores, tais como a presença de nuvens no imageamento do pixel, sombra provocada pelas nuvens nos pixels da adjacência, qualidade ruim no imageamento do pixel nas bandas do vermelho e do infravermelho-próximo, fumaça, chuva e ventos fortes.

A fim de alcançar um perfil temporal do NDVI que traduza o comportamento do alvo (canasoca) em estudo, minimizando a influência de ruídos, as seguintes etapas são empregadas: 1) emprego de um limiar superior $(0,92)$ e inferior $(0,20)$ para o NDVI, a fim de descartar a influência da saturação do NDVI e do solo/palha; 2) uso da banda de controle de qualidade (QC), a fim de descartar valores de pixels com incertezas de qualidade, referente ao imageamento e correção atmosférica, não imageados e contaminados com nuvem; 3) eliminação de valores discrepantes, possivelmente provocados por eventos naturais, tais como a influência da chuva sobre a resposta espectral da planta e ventos fortes, do meio ambiente ou provocados pelo ser humano, tal como a fumaça; e 4) suavização do perfil temporal do NDVI MODIS em cada safra através do filtro Savitzky-Golay (CHEN et al., 2004; SAVITZKY \& GOLAY, 1964). A ilustração (a) da Figura 5 apresenta o perfil temporal do NDVI MODIS a bordo do satélite TERRA, de três safras para a canasoca nas microrregiões 3 e 5, antes da filtragem utilizando os dados da banda QC mostrando a presença de ruídos. A ilustração (b) da Figura 5 apresenta o perfil temporal do NDVI MODIS após o emprego da filtragem com os dados da banda QC, evidenciando que ainda há ruídos. O corte da cana-de-açúcar nos talhões ocorre de forma gradual (ao longo de vários dias), portanto também é necessário identificar o período de início e término de corte (identificação ' 1 ' da ilustração 'c' da Figura 5) a fim de representar adequadamente o perfil temporal do NDVI. Da mesma forma, logo após o corte da cultura da cana-de-açúcar, o solo exposto e a presença de palha da cana-de-açúcar no solo (identificação '2' da ilustração 'c' da Figura 5) influenciam nos valores do NDVI e, consequentemente, também é importante representar adequadamente o perfil temporal do NDVI neste período. A ilustração (d) da Figura 5 apresenta a visualização gráfica do perfil temporal do NDVI MODIS para a microrregião 3 após o emprego de todas as etapas de filtragem e suavização dos dados.

Durante a etapa de identificação de valores discrepantes, os quais influenciam negativamente no aspecto do perfil temporal do NDVI, pela técnica de suavização dos dados pelo filtro Savitzky-Golay, uma janela temporal percorre os valores de NDVI de uma safra e, ao identificar uma variação significativa no valor corrente, analisado, em função dos dados anteriores, levando em 
conta a tendência dos próximos valores, descarta-se o dado corrente caso este apresente uma variação percentual superior a $20 \%$ no valor NDVI, no período de 8 dias, que é o tempo entre uma imagem e outra neste trabalho. Esse dado descartado é classificado como um valor contendo ruído, provavelmente provocado por algum fenômeno natural pontual naquela data de imageamento, e não é atribuído destaque para fins de análise do perfil NDVI ao longo do ciclo fenológico. Como a data de corte é um dado que é conhecido, pois está no banco de dados obtido da usina de cana-de-açúcar, é possível, temporalmente, detectar variações representativas nos valores individuais dos pixels, na data de imageamento anterior e posterior à data de corte da cultura. A partir da variância entre os pixels dos valores NDVI no período referente às datas anterior e posterior ao corte, é possível identificar quantos dias, efetivamente, a composição NDVI dos talhões, agrupados em uma determinada microrregião, foram influenciados durante o corte da cana-de-açúcar.

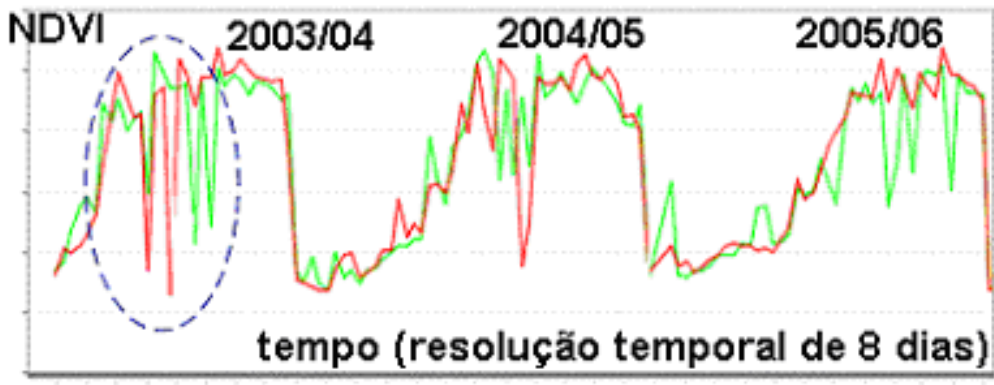

(a) Dados brutos

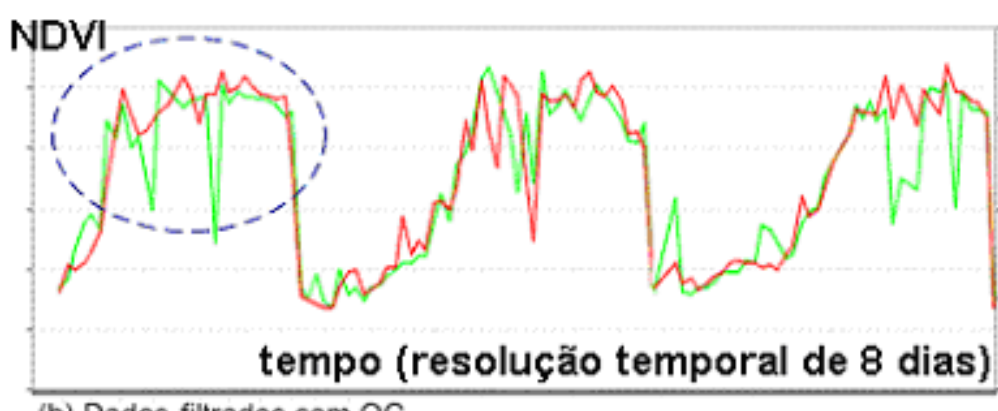

(b) Dados filtrados com QC

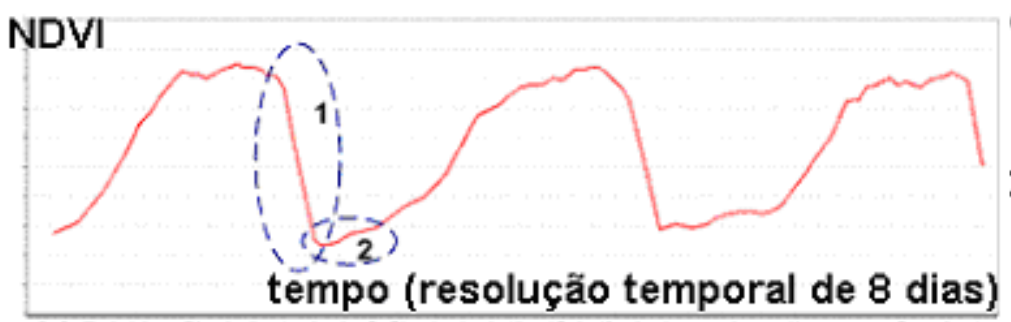

(c) Dados filtrados com QC, remoçăo Outliers, suavização com Savitzky-Golay

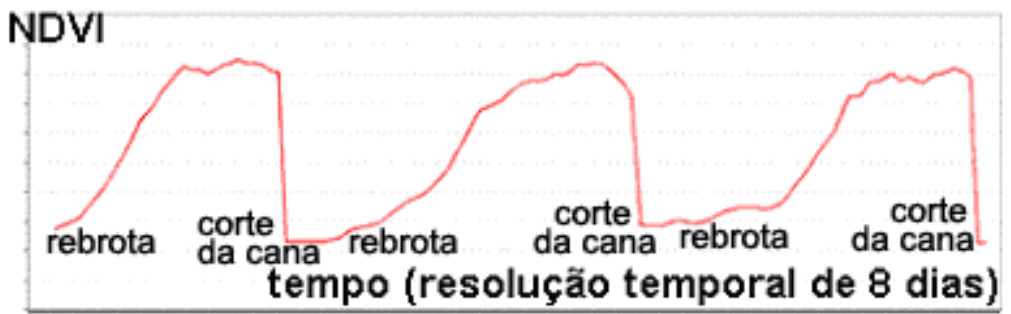

Correções requeridas

1- Influência do período de corte

2- Influência do solo exposto e palha

Exemplo dos perfis temporais do NDVI com a presença de ruídos.

vermelho, a Em azul, a elipsóide destaca uma região de ruídos.

Os ruidos em destaque na região azul foram minimizados com uso da banda de controle de qualidade (QC)

(d) Dados filtrados com QC, remoçâo Outliers, suavizaçăo com Savitzky-Golay, correçőes 1 e 2

FIGURA 5. Suavização de ruídos presentes no perfil temporal do NDVI MODIS TERRA. Noise smoothing on the NDVI MODIS TERRA temporal profile.

A exibição gráfica do perfil temporal do NDVI MODIS, ilustrado na Figura 5, é realizada de forma automática, através de programa desenvolvido no trabalho, em linguagem de programação $J a v a$, a partir dos dados do fator de refletância bidirecional de superfície relativo ao comprimento 
de onda do vermelho e do infravermelho-próximo, do produto MOD09Q1, contidos no esquema schPixel do banco de dados do trabalho. O aplicativo realiza a filtragem de ruídos detectados no perfil temporal do NDVI e promove uma suavização que é representativa de um ciclo fenológico da cana-soca.

O conhecimento das fases fenológicas do ciclo da cultura é essencial para maximizar a produção de cana-de-açúcar. Neste trabalho, o desenvolvimento da cana-soca foi separado em quatro fases principais: 1 - Estabelecimento; 2 - Perfilhamento; 3 - Formação dos Colmos; e 4 Amadurecimento. As fases do ciclo da cana-soca foram divididas em 8 estágios, conforme apresentado na Tabela 2. Essa adaptação foi realizada a fim de considerarem as especificidades da cana-soca na maturação tardia, nos perfis temporais do NDVI.

TABELA 2. Fases e estágios de crescimento da cana-soca propostas neste trabalho (DOORENBOS \& KASSAM, 1981). Phases and growing stages of stubble-cane proposed in this study.

\begin{tabular}{|c|c|}
\hline Fases de Crescimento & Estágios de desenvolvimento da vegetação \\
\hline 1 - Estabelecimento & (e1) Rebrota até $0,25 \%$ da cobertura vegetal \\
\hline \multirow{2}{*}{2 - Perfilhamento } & (e2) $0,25 \%$ até $0,50 \%$ da cobertura vegetal \\
\hline & (e3) $0,50 \%$ até $0,75 \%$ da cobertura vegetal \\
\hline \multirow{3}{*}{3 - Formação dos colmos } & (e4) $0,75 \%$ até a cobertura vegetal \\
\hline & (e5) Grande crescimento vegetativo \\
\hline & (e6) Crescimento (parte final) \\
\hline \multirow{2}{*}{4 - Amadurecimento } & (e7) Início da senescência \\
\hline & (e8) Amadurecimento \\
\hline
\end{tabular}

A arquitetura do software Cliente/Servidor, ilustrada na Figura 6, compreende o aplicativo cliente utilizado para a visualização do perfil temporal NDVI, e o sistema gerenciador de banco de dados relacional PostgreSQL, o qual armazena o banco de dados desenvolvido para este trabalho.

O aplicativo foi desenvolvido de forma modular em componentes de software, adoção de design patterns, tais como Data Access Object, Transfer Object, Abstract Factory, Factory Method, Facade, Model-View-Controller, e é constituído de três camadas de software: 1) visualização gráfica; 2) filtragem de ruídos e suavização do perfil temporal do NDVI; e 3) acesso aos dados do banco de dados. A comunicação entre o cliente e o servidor ocorre através do protocolo de comunicação Java Database Connectivity.

As consultas são enviadas ao servidor através da linguagem de consulta SQL-92, que as processa e retorna apenas os dados solicitados, deixando a carga maior do processamento ao servidor. A consulta a um determinado perfil temporal do NDVI requer como parâmetros básicos: a identificação da microrregião desejada e o ano/safra da cultura.

A utilização da banda de controle de qualidade na filtragem dos dados demonstrou não ser o suficiente para capturar todos os ruídos presentes nas imagens NDVI MODIS na composição de 8 dias. Portanto, para obter um perfil temporal do NDVI que represente de maneira suave a evolução de uma safra na cultura da cana-de-açúcar, é necessário combinar várias etapas de filtragem, conforme apresentadas neste trabalho. O filtro Savitzky-Golay demonstra ser uma eficiente abordagem para a suavização dos dados, contudo valores discrepantes significativos influenciam no perfil temporal do NDVI e, portanto, devem ser previamente tratados para possibilitar a apresentação mais natural ao comportamento do alvo em estudo neste trabalho - a cultura da cana-de-açúcar. 


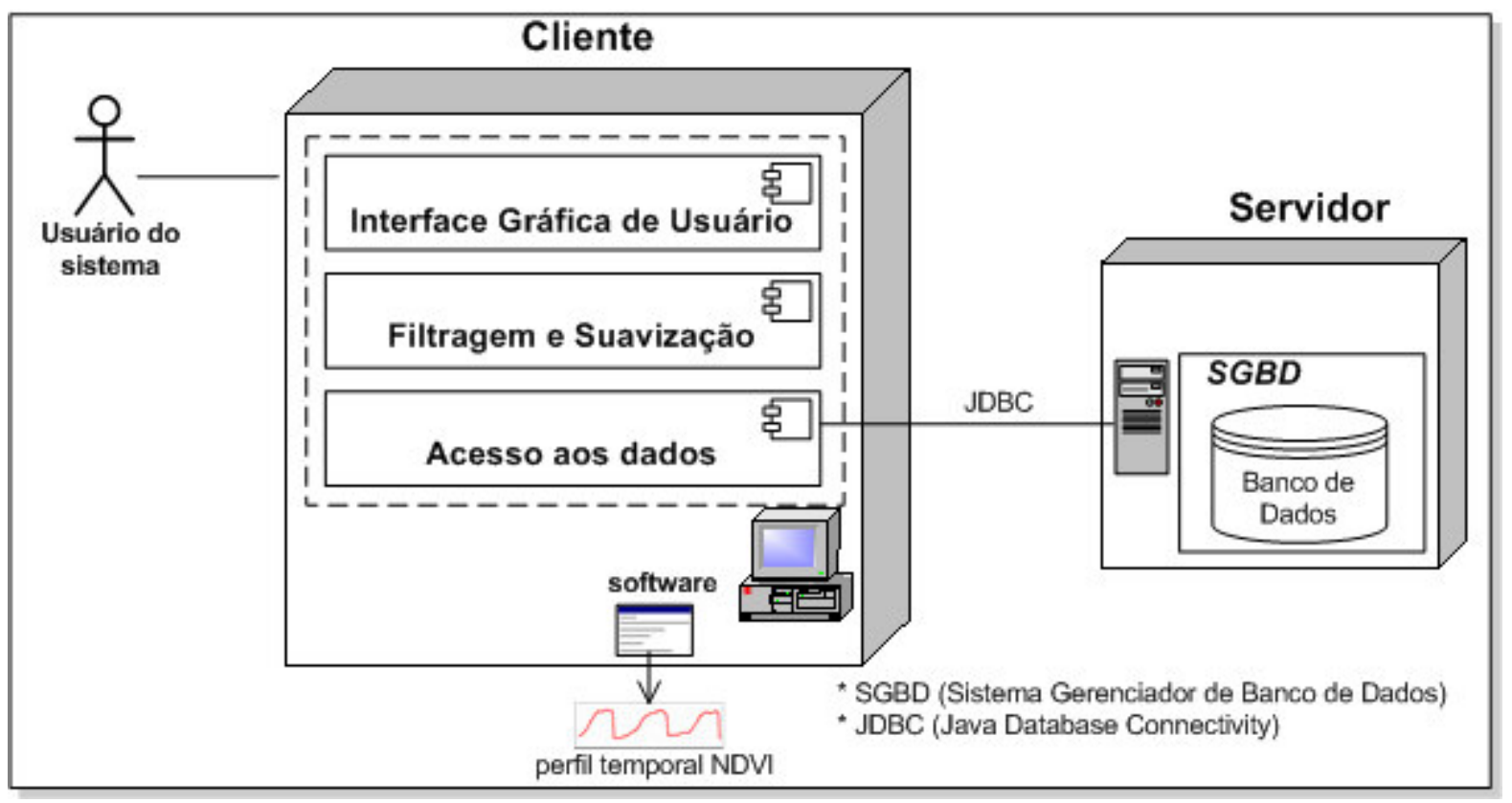

FIGURA 6. Arquitetura do software para a exibição gráfica do perfil temporal do NDVI MODIS. Software architecture graphics used to present the NDVI MODIS temporal profile.

O corte da cana-de-açúcar nos talhões ocorre, de forma gradual, ao longo de vários dias, portanto também é necessário identificar o período de início e término de corte a fim de representar adequadamente o perfil temporal do NDVI. Da mesma forma, logo após o corte da cultura da cana-de-açúcar, o solo exposto e a presença de palha da cana-de-açúcar no solo influenciam nos valores de NDVI e, consequentemente, também é importante representar adequadamente o perfil temporal do NDVI neste período.

\section{RESULTADOS E DISCUSSÃO}

Na Figura 7, ilustra-se o perfil temporal do NDVI, para a microrregião 3 nas safras de 2004/2005 e 2005/2006. Conforme observado na Figura 7, o ápice do NDVI, na safra de 2004/2005, ocorreu a aproximadamente 160 dias após o início da rebrota e na safra de 2005/2006, aos 110 dias após o início da rebrota. A safra de 2004/2005 é de segundo corte, em 29 de novembro de 2005, produzindo 87,6 $\mathrm{t} \mathrm{ha}^{-1}$. A safra de 2005/2006 é de terceiro corte, realizado em 11 de novembro de 2006, produzindo 60,3 $\mathrm{t} \mathrm{ha}^{-1}$.

Apesar de, naturalmente, haver redução de produtividade entre estes dois anos, do segundo para o terceiro corte não há uma diferença significativa de produtividade como neste caso. Assim, o que pode ser constatado é que houve uma diferença entre os perfis temporais do NDVI do ano de 2004/2005 para aquele de 2005/2006, que pode ter ocorrido devido a problemas de chuva ou à falta dela ou a algum outro fator que fez a cultura atingir o ápice em data anterior à safra passada e, rapidamente, entrar em senescência.

Esse resultado produz uma relação direta entre o perfil temporal do NDVI e a produtividade final da cultura. A possibilidade de acompanhar o perfil temporal do NDVI durante o período de crescimento e a verificação de onde houve o problema, isto é, em qual fase (estabelecimento, perfilhamento, formação dos colmos e amadurecimento), ajuda a relacionar o perfil temporal do NDVI com o resultado final do ciclo, que é a produtividade. 


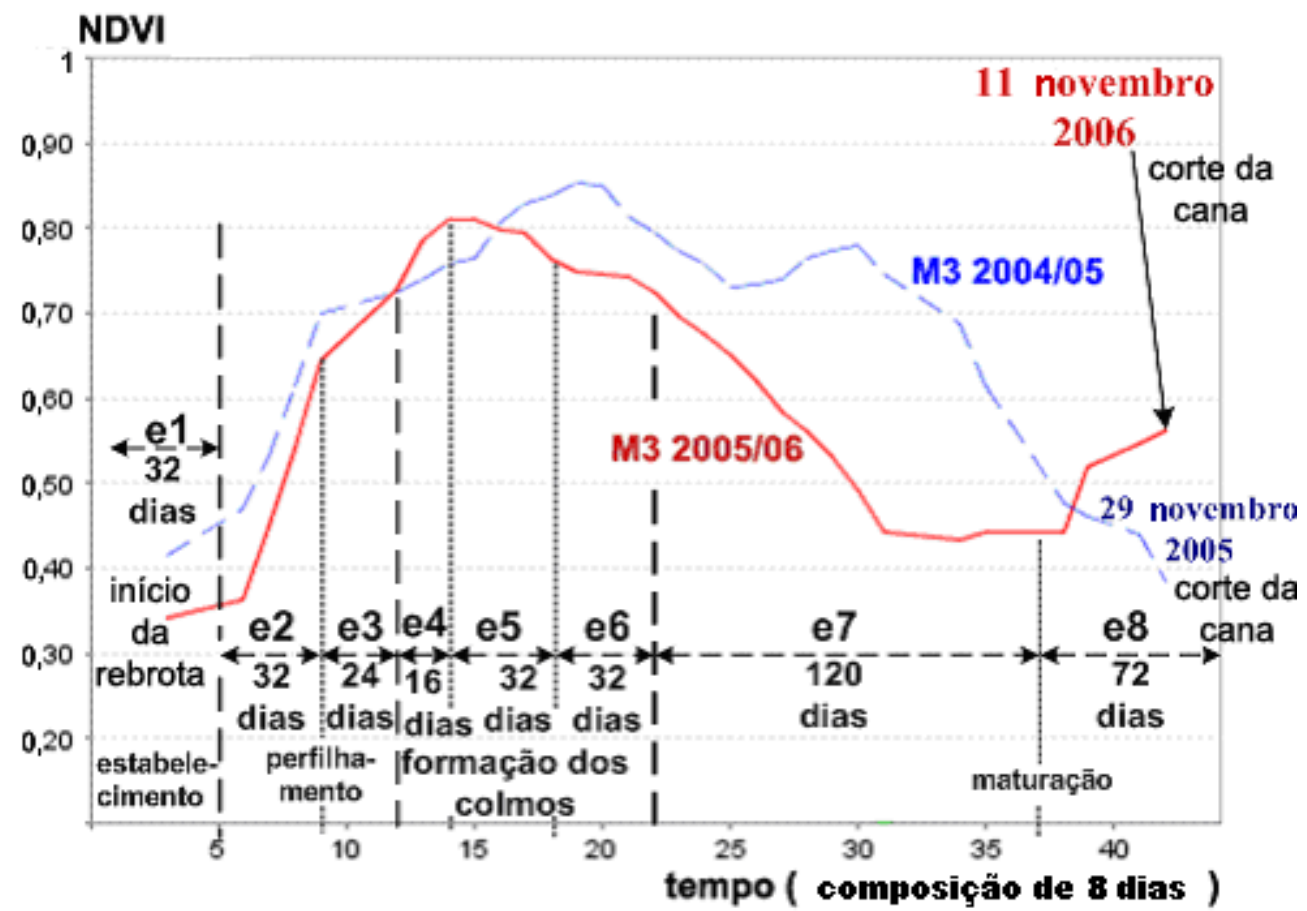

FIGURA 7. Perfil temporal do NDVI, microrregião 3 (M3), nas safras de 2004/2005 e 2005/2006. NDVI temporal profile in microregion 3 (M3) during the 2004/2005 and 2005/2006 harvesting season.

Na Figura 8, ilustra-se o perfil temporal do NDVI, para a microrregião 5, nas safras de 2004/2005 e 2005/2006. Conforme observado na Figura 8, o ápice do NDVI para a safra de 2004/2005 ocorreu a aproximadamente 160 dias após o início da rebrota e, para a safra de 2005/2006, aos 110 dias após o início da rebrota. A safra de 2004/2005 é de segundo corte, em 28 de novembro de 2005, produzindo 88,2 $\mathrm{t} \mathrm{ha}^{-1}$. A safra de 2005/2006 é de terceiro corte, em 11 de novembro de 2006, produzindo $62,0 \mathrm{t} \mathrm{ha}^{-1}$.

A produtividade final da cultura da microrregião 5, nas safras de 2004/2005 e 2005/2006, é diferente. Conforme observado na Figura 8, é constatado que houve uma diferença entre os perfis temporais do NDVI do ano de 2004/2005 para aquele de 2005/2006, da mesma maneira que o ocorrido na microrregião 3. Podem aqui ser levantados os mesmos problemas levantados na análise da microrregião 3. A menor área de abrangência sob o perfil temporal do NDVI esteve associada à menor produtividade, no final. Nesses casos, a menor área correspondeu à fase de formação de colmos e ao início do amadurecimento.

Na Figura 9, ilustra-se o perfil temporal do NDVI, para as microrregiões 3 e 5. Conforme observado na Figura 9, o ápice do NDVI, para ambas as safras, ocorreu a aproximadamente 110 dias após o início da rebrota. A microrregião 3, na safra de 2005/2006, é de terceiro corte, em 11 de novembro de 2006, produzindo 60,3 $\mathrm{t} \mathrm{ha}^{-1}$. A microrregião 5, na safra de 2005/2006, é de terceiro corte, em 11 de novembro de 2006, produzindo 62,0 $\mathrm{t} \mathrm{ha}^{-1}$. A produtividade final da cultura das microrregiões 3 e 5, na safra de 2005/2006 são semelhantes. Esses perfis temporais do NDVI, comparados, demonstraram ser significativamente semelhantes, corroborando os resultados anteriores em que o perfil temporal do NDVI pode ser um indicador de qualidade da produtividade final. 


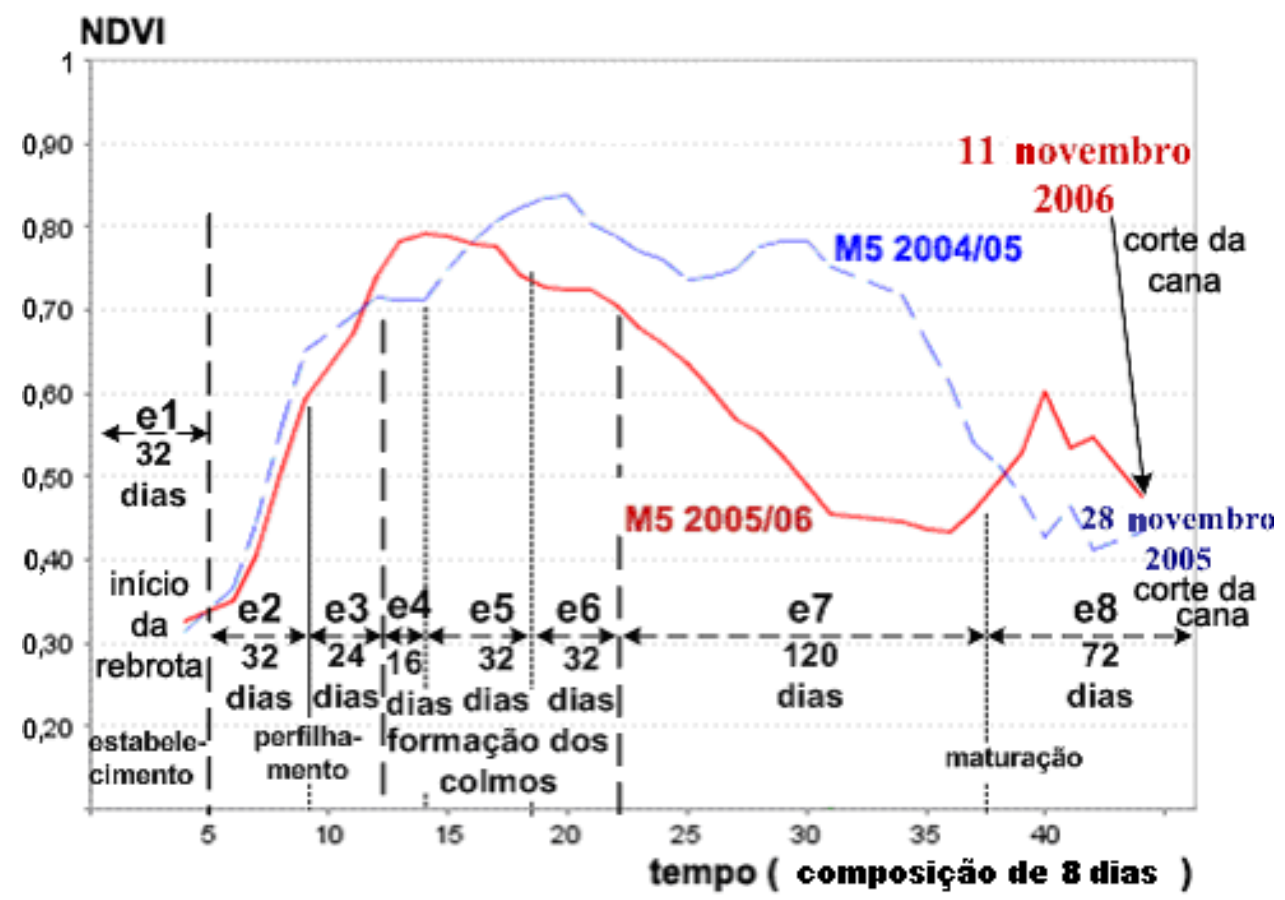

FIGURA 8. Perfil temporal do NDVI, microrregião 5 (M5), nas safras de 2004/2005 e 2005/2006. NDVI temporal profile in microregion 5 (M5) during the 2004/2005 and 2005/2006 harvesting season.

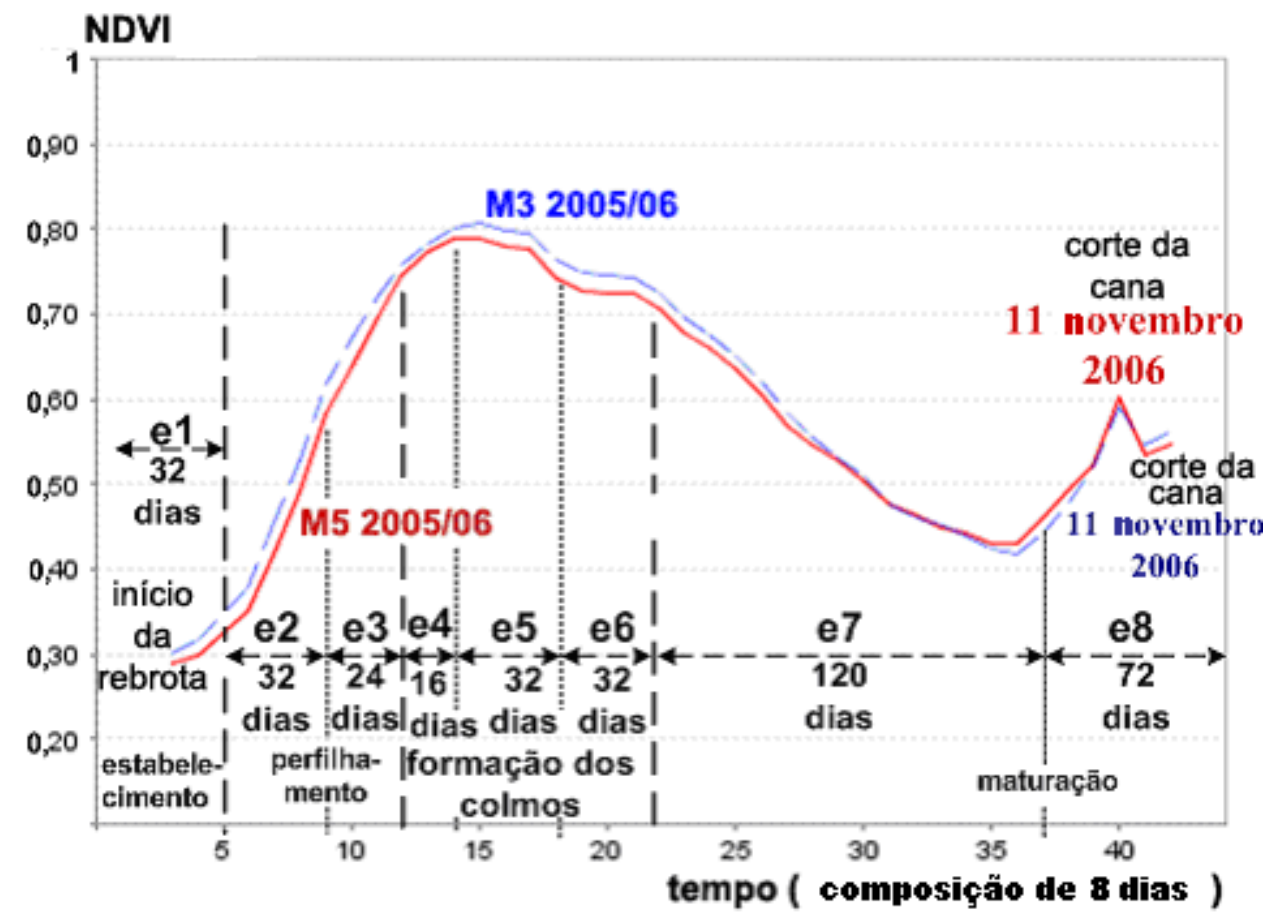

FIGURA 9. Perfil temporal do NDVI, microrregiões 3 (M3) e 5 (M5). NDVI temporal profile in microregions 3 (M3) and 5 (M5).

Para examinar os resultados anteriores, foi gerado o perfil temporal do NDVI da microrregião 4. Essa microrregião apresentou produtividades semelhantes às microrregiões 3 e 5 , nas safras de 2004/2005 e 2005/2006.

Na Figura 10, ilustra-se o perfil temporal do NDVI. Conforme observado na Figura 10, o ápice do NDVI, na safra de 2004/2005, ocorreu a aproximadamente 160 dias após o início da rebrota e, na safra de 2005/2006, aos 140 dias após o início da rebrota. A safra de 2004/2005 é de 
segundo corte, em 25 de novembro de 2005, produzindo 84,0 $\mathrm{t} \mathrm{ha}^{-1}$. A safra de 2005/2006 é de terceiro corte, em 11 de novembro de 2006, produzindo $67,0 \mathrm{t} \mathrm{ha}^{-1}$.

A produtividade final da cultura da microrregião 4, nas safras de 2004/2005 e 2005/2006, são diferentes. Conforme observado na Figura 10, é constatado que houve uma diferença entre os perfis temporais do NDVI do ano de 2004/05 para aquele de 2005/2006. Mais uma vez houve coerência entre os perfis temporais do NDVI e a produtividade final.

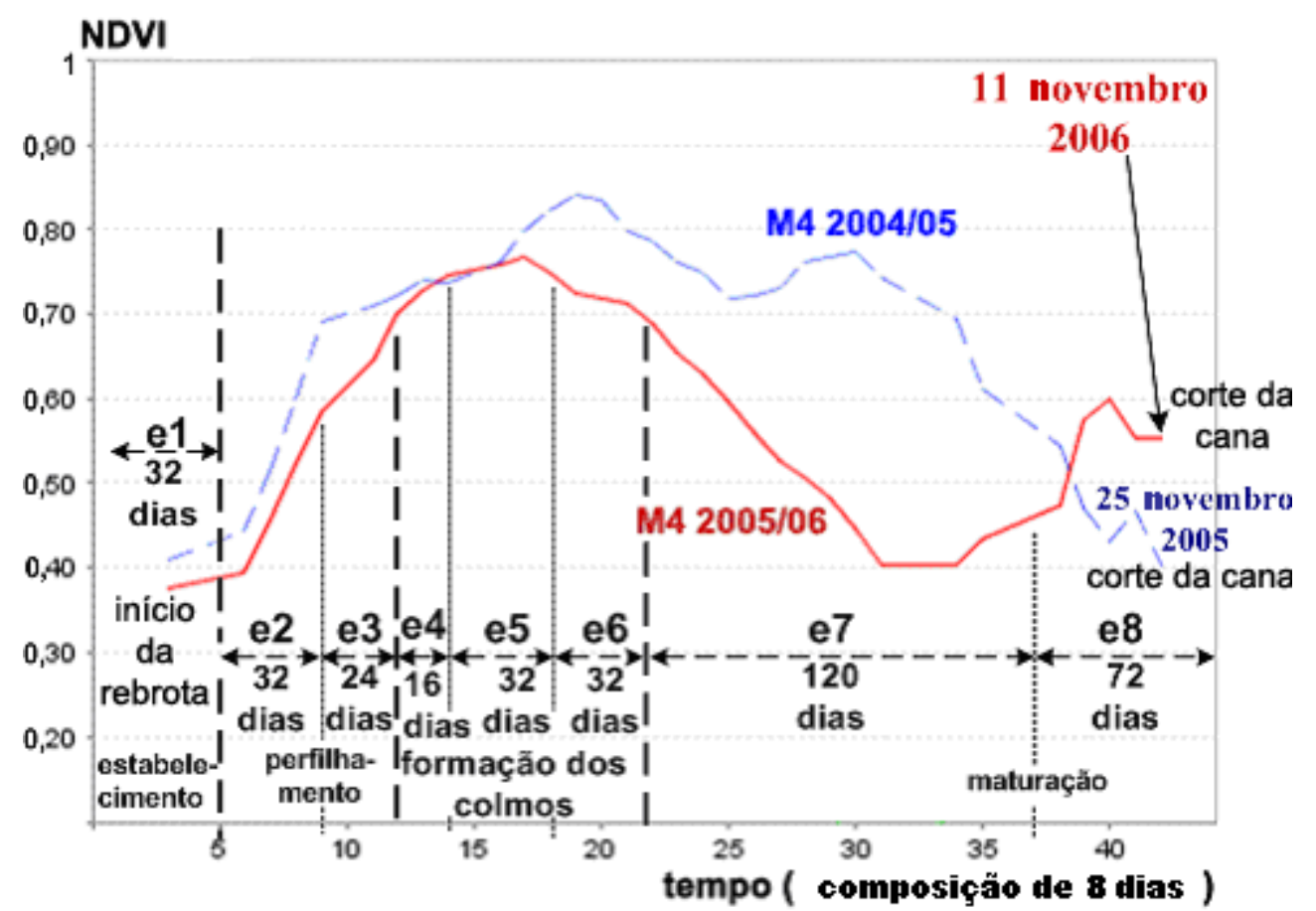

FIGURA 10. Perfil temporal do NDVI, microrregião 4 (M4), nas safras de 2004/2005 e 2005/2006. NDVI temporal profile in microregion 4 (M4) during the 2004/05 and 2005/2006 harvesting season.

Na Figura 11, ilustra-se o perfil temporal do NDVI, para as microrregiões 6 e 9. Conforme observado na Figura 11, o ápice do NDVI, em ambas as safras, ocorreu a aproximadamente 110 dias após o início da rebrota, e a fase de amadurecimento foi a que apresentou maior variação percentual entre as áreas dos perfis temporais do NDVI. A microrregião 6, na safra de 2005/2006, é de segundo corte, em 21 de agosto de 2006, produzindo 90,0 $\mathrm{t} \mathrm{ha}^{-1}$. A microrregião 9, na safra de 2005/2006, é de segundo corte, em 5 de agosto de 2006, produzindo 81,0 $\mathrm{t} \mathrm{ha}^{-1}$.

Essas microrregiões apresentam variedades distintas, no entanto não são significativas do ponto de vista de análise do perfil temporal do NDVI. A combinação de fatores, como um solo pobre, uma variedade não resistente às características do solo e uma possível deficiência hídrica, principalmente na fase de amadurecimento, pode ter influenciado na evolução do perfil temporal do NDVI e proporcionado uma produtividade um pouco menor no final da safra da microrregião 9.

Conforme ilustrado na Figura 12 e de acordo com as características das microrregiões de estudo neste trabalho, ficou constatado que, na cana-soca de maturação Tardia, períodos de rebrota e corte semelhantes entre os perfis temporais do NDVI, e produtividades semelhantes, apresentam semelhantes perfis temporais do NDVI. A microrregião 3, na safra de 2004/2005, é de segundo corte, em 29 de novembro de 2005, produzindo 87,6 t ha ${ }^{-1}$. A microrregião 5, na safra de 2004/2005, é de segundo corte, em 28 de novembro de 2005, produzindo 88,2 $\mathrm{t} \mathrm{ha}^{-1}$. A microrregião 3 , na safra de 2005/2006, é de terceiro corte, em 11 de novembro de 2006, produzindo 60,3 $\mathrm{t} \mathrm{ha}^{-1}$. A microrregião 5, na safra de 2005/2006, é de terceiro corte, em 11 de novembro de 2006, produzindo $62,0 \mathrm{tha}^{-1}$. 


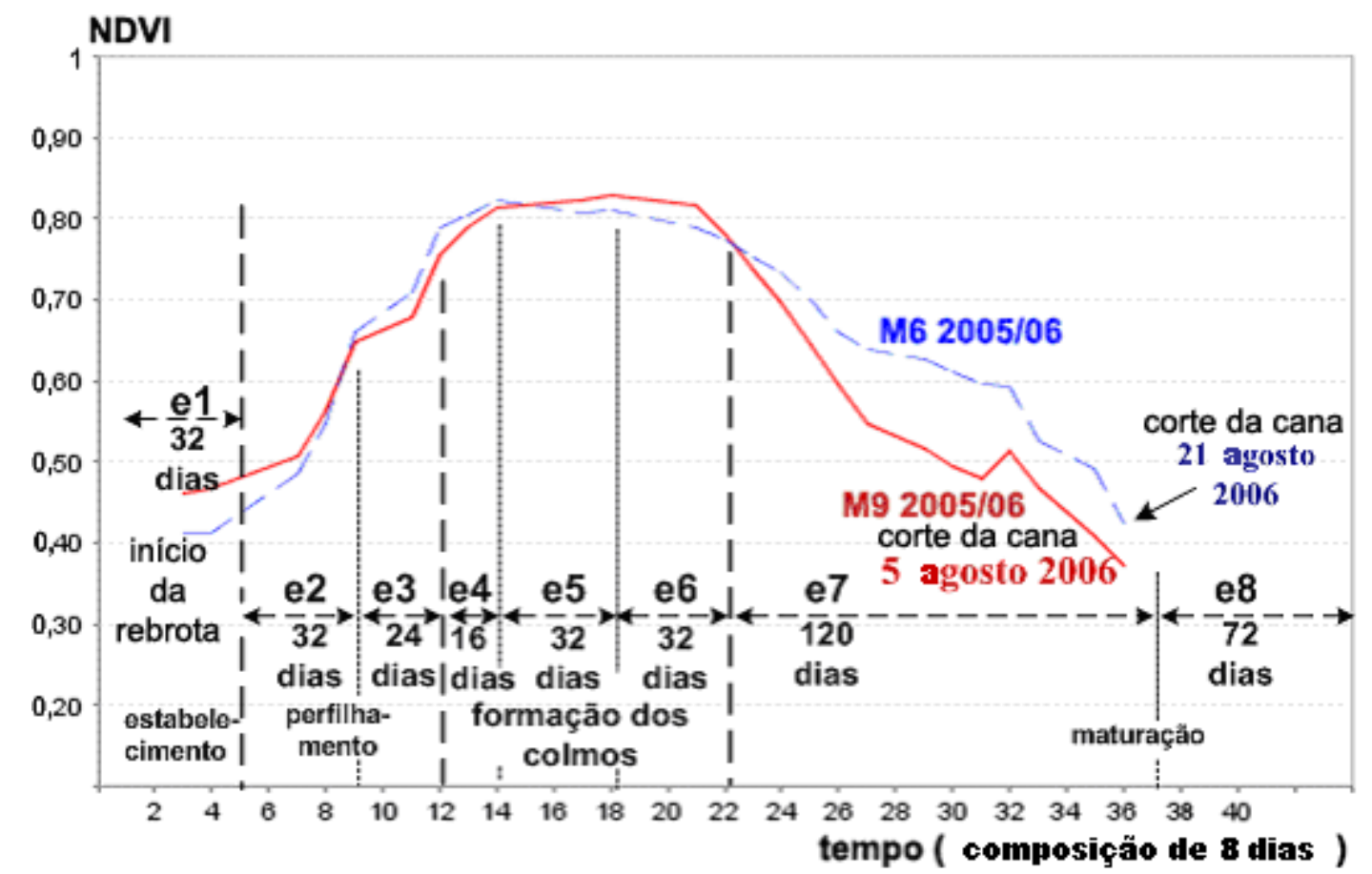

FIGURA 11. Perfil temporal do NDVI, microrregiões 6 (M6) e 9 (M9). NDVI temporal profile in microregions 6 (M6) and 9 (M9).
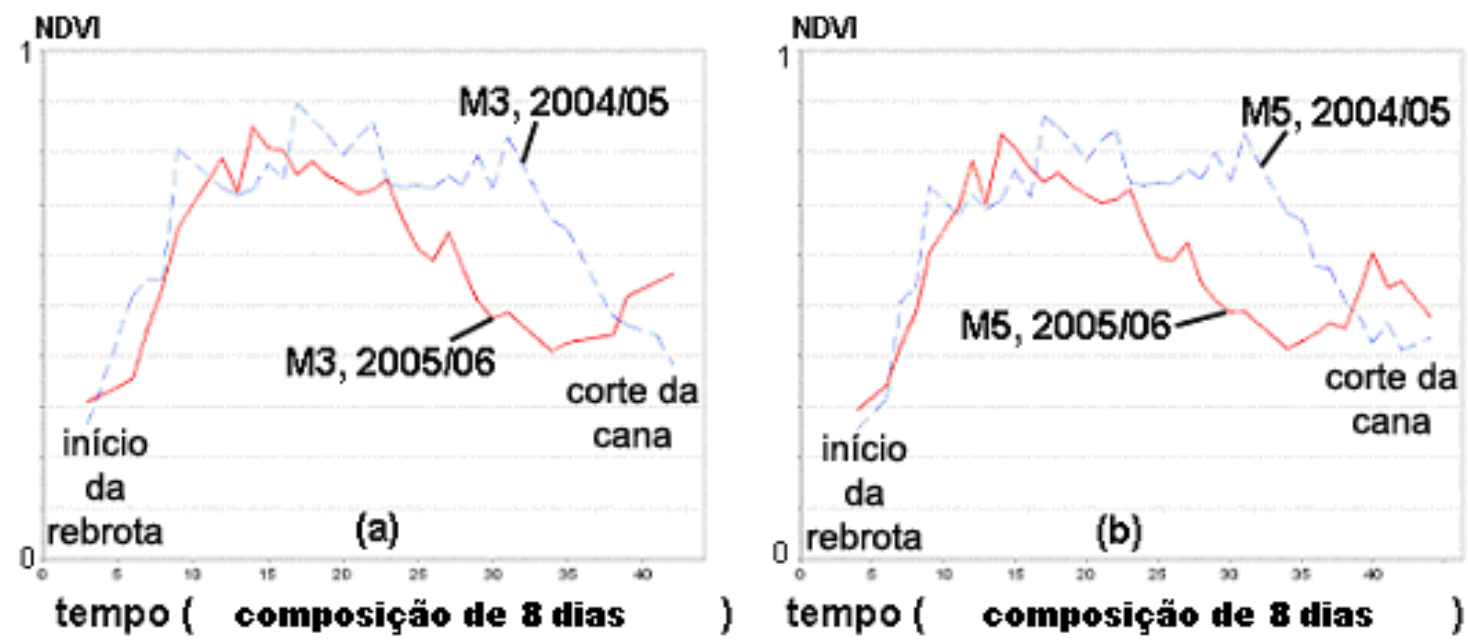

FIGURA 12. Perfil temporal do NDVI, microrregiões 3 (M3) e 5 (M5). NDVI temporal profile in microregions 3 (M3) and 5 (M5).

Outra constatação foi que o patamar entre o final do perfilhamento até o começo da senescência (e3 a e7) de uma variedade dita tardia é bem longo, e qualquer variação neste patamar influenciou na produtividade final, negativamente.

\section{CONCLUSÕES}

O objetivo do trabalho de obter o perfil temporal do NDVI, em uma determinada microrregião e safra, através de uma ferramenta, foi alcançado.

O perfil temporal do NDVI MODIS obtido a partir do produto MOD09Q1 mostrou-se sensível às variações fenológicas apresentadas pela cana-soca de maturação Tardia e, portanto, conclui-se que essa composição é capaz de subsidiar o monitoramento das mudanças fenológicas na cultura da cana-de-açúcar. 


\section{AGRADECIMENTOS}

À Faculdade de Engenharia Agrícola da Universidade Estadual de Campinas (UNICAMP) e ao Centro de Pesquisas Meteorológicas e Climáticas Aplicadas à Agricultura (CEPAGRI), pela infraestrutura disponibilizada para o desenvolvimento deste trabalho; à FAPESP e ao Instituto Virtual FAPESP - Microsoft Research (projeto eFarms), pelo suporte ao trabalho.

\section{REFERÊNCIAS}

BENVENUTI, F.A. Relação de índices espectrais de vegetação com a produtividade da cana-de-açúcar e atributos edáficos. 2005. 103 f. Dissertação (Mestrado em Planejamento e Desenvolvimento Rural Sustentável) - Faculdade de Engenharia Agrícola, Universidade de Campinas, Campinas, 2005.

CASAGRANDE, A.A. Tópicos de morfologia e fisiologia da cana-de-açúcar. Jaboticabal: FUNEP, 1991. $157 \mathrm{p}$.

CHEN, J.; JÖNSSON, P.; TAMURA, M.; GU, Z.; MATSUSHITA, B.; EKLUNDH, L. A simple method for reconstructing a high-quality NDVI time-series data set based on the Savitzky-Golay filter. Remote Sensing of Environment, New York, v.91, n.3-4, p.332-334, 2004.

DILLEWIJN, C.V. Botany of sugarcane. Waltham: Chronica Botânica, 1952. 371 p.

DOORENBOS, J.; KASSAM, A.H. Yield response to water. $2^{\text {nd }}$ ed. Rome: FAO, 1981. 193 p. (Irrigation and Drainage Paper, 33).

ELVIDGE, C.D.; CHEN, Z. Comparison of broad-band and narrow-band red and near-infrared vegetation indices. Remote Sensing of Environment, New York, v.54, n.1, p.38-48, 1995.

EPIPHANIO, J.C.N.; HUETE, A.R. Influence of sun-view geometries on the relationships among vegetation indices, LAI, and absorbed PAR. In: INTERNATIONAL GEOSCIENCE AND REMOTE SENSING SYMPOSIUM, 14., 1994, Pasadena. Proceedings... Piscataway: IEEE, 1994, v.3, p.1.455-1.457.

GSFC/NASA. Moderate Resolution Imaging Spectroradiometer (MODIS): technical specifications. Disponível em: <http://modis.gsfc.nasa.gov/about/design.php>. Acesso em: 5 nov. 2008.

HUETE, A.; JUSTICE, C.; LEEUWEN, W. van. MODIS vegetation index (MOD13). In: EOS MODIS Algorithm-Theoretical Basis Document, Version 3. Tucson: University of Arizona, April 1999. $129 \mathrm{p}$.

PELLEGRINO, G.Q.; PINTO, H.S.; ZULLO JÚNIOR, J.; ALMEIDA, C.A.S. de. Estimativa do índice de área foliar e da massa seca de colmos da cana de açúcar a partir de dados espectrais de campo. Revista Brasileira de Agrometeorologia, Santa Maria, v.15, n.1, p.49-58, 2007.

PONZONI, F.J. Comportamento espectral da vegetação. In: reflectância dos alvos naturais. Brasília: Editora UnB, 2001. p.157-199.

Sensoriamento Remoto -

PostgreSQL. PostgreSQL 8.2 documentation. Disponível em: <http://www.postgresql.org/>. Acesso em: 18 jan. 2008.

ROUSE, J.W.; HAAS, R.H.; SCHELL, J.A.; DEERING, D.W. Monitoring vegetation systems in the great plains with ERTS. In: EARTH RESOURCES TECHNOLOGY SATELLITE-1

SYMPOSIUM, 3., 1973, Washington. Proceedings... Washington: NASA, Goddard Space Flight Center, 1973. v.1, p.309-317.

RUDORFF, B.F.T.; BATISTA, G.T. Yield estimation of sugarcane based on agrometeorological spectral models. Remote Sensing of Environment, New York, v.33, n.1, p.183-192, 1990.

SAVITZKY, A.; GOLAY, M.J.E. Smoothing and differentiation of data by simplified least squares procedures. Analytical Chemistry, Gdansk, v.36, n.8, p.1.627-1.639, 1964. 
SIMÕES, M. dos S.; ROCHA, J.V.; LAMPARELLI, R.A.C. Orbital spectral variables, growth analysis and sugarcane yield. Scientia Agricola, Piracicaba, v.66, n.4, p.451-461, 2009.

SIMÕES, M. dos S.; ROCHA, J.V.; LAMPARELLI, R.A.C. Spectral variables, growth analysis and yield of sugarcane. Scientia Agricola, Piracicaba, v.62, n.3, p.199-207, 2005.

TUCKER, C.J. Red and photographic infrared linear combinations for monitoring vegetation. Remote Sensing of Environment, New York, v.8, n.2, p.127-150, 1979.

TURNER, D.P.; COHEN, W.B.; KENNEDY, R.E.; FASSNACHT, K.S.; BRIGGS, J.M.

Relationships between leaf area index and Landsat TM spectral vegetation indices across three temperate zone sites. Remote Sensing of Environment, New York, v.70, n.1, p.52-68, 1999.

USGS/LPDAAC. Imagens dos satélites MODIS/TERRA disponibilizadas por U.S. Geological Survey / Land Processes Distributed Active Archive Center. Disponível em: <http://lpdaac.usgs.gov/modis/dataproducts.asp>. Acesso em: 16 abr. 2007. 